Review

\title{
Oxidative Stress Mechanisms Underlying Parkinson's Disease-Associated Neurodegeneration in C. elegans
}

\author{
Sudipta Chakraborty $^{1,2}$, Julia Bornhorst ${ }^{3}$, Thuy T. Nguyen ${ }^{2,4}$ and Michael Aschner ${ }^{2,3,4, *}$ \\ 1 Neuroscience Graduate Program, Vanderbilt University Medical Center, Nashville, TN 37232 , \\ USA; E-Mail: sudipta.chakraborty@vanderbilt.edu \\ 2 Center in Molecular Toxicology, Vanderbilt University Medical Center, Nashville, TN 37232, \\ USA; E-Mail: thuy.t.nguyen@vanderbilt.edu \\ 3 Department of Pediatrics, Vanderbilt University Medical Center, Nashville, TN 37232, USA; \\ E-Mail: bornhorst@uni-muenster.de \\ 4 Department of Pharmacology, Vanderbilt University Medical Center, Nashville, TN 37232, USA \\ * Author to whom correspondence should be addressed; E-Mail: michael.aschner@einstein.yu.edu; \\ Tel.: +1-718-430-2317.
}

Received: 14 August 2013; in revised form: 8 October 2013 / Accepted: 16 October 2013 / Published: 21 November 2013

\begin{abstract}
Oxidative stress is thought to play a significant role in the development and progression of neurodegenerative diseases. Although it is currently considered a hallmark of such processes, the interweaving of a multitude of signaling cascades hinders complete understanding of the direct role of oxidative stress in neurodegeneration. In addition to its extensive use as an aging model, some researchers have turned to the invertebrate model Caenorhabditis elegans (C. elegans) in order to further investigate molecular mediators that either exacerbate or protect against reactive oxygen species (ROS)-mediated neurodegeneration. Due to their fully characterized genome and short life cycle, rapid generation of $C$. elegans genetic models can be useful to study upstream markers of oxidative stress within interconnected signaling pathways. This report will focus on the roles of C. elegans homologs for the oxidative stress-associated transcription factor Nrf2, as well as the autosomal recessive, early-onset Parkinson's disease (PD)-associated proteins Parkin, DJ-1, and PINK1, in neurodegenerative processes.
\end{abstract}

Keywords: oxidative stress; neurodegeneration; Parkinson's disease; C. elegans; DJ-1; Parkin; PINK1; Nrf2 


\section{Introduction}

The prevalence of neurodegenerative disorders, such as Parkinson's disease (PD), has been increasing at a disconcerting rate. As age is the most significant risk factor for the development of this and other neurological diseases, longer lifespan worldwide has resulted in an increased global burden that is both financial and emotional in nature. In addition to expensive costs for treatments that do not fully resolve all symptoms, the quality of life for ailing patients is poor. Moreover, caretakers are faced with the challenge of providing support to patients suffering from the disease, which inevitably takes a significant toll on their own financial, physical and emotional well being. Significant headway has been made towards elucidating the etiology of PD, characterized by the hallmark loss of dopaminergic (DAergic) neurons in the substantia nigra pars compacta ( $\mathrm{SNpc}$ ) region of the brain [1]. This selective cell loss results in both motor and cognitive deficits, with cardinal symptoms of bradykinesia, rigidity, tremor and postural instability that are accompanied by emotional and cognitive problems [2]. However, the true mechanisms behind PD pathophysiology remain unknown, resulting in unsustainable treatment options that only provide symptomatic relief and do not target the original cause of the disease.

While the majority of PD cases are sporadic in nature (idiopathic PD or IPD), about $10 \%-20 \%$ of cases are well documented as having genetic causes. Many PD-associated genes have been identified, including DJ-1, PINK1, PARKIN, NURR1, LRRK2, UCH-L1, and SNCA [2]. Despite the known functions of these PD-associated genes, their role within interconnected signaling pathways involved in PD pathogenesis remains highly complicated and not yet fully understood. Interestingly, a shared role among many of these disease genes is participation in oxidative stress pathways. In fact, oxidative stress is thought to be one of the primary mechanisms behind the onset and progression of the DAergic-specific neurodegeneration in PD [3], as highly neurotoxic free radicals are generated both through the metabolism of dopamine and its own auto-oxidation that can be enhanced by exposure to environmental stressors [4]. Both increased oxidative stress and mitochondrial dysfunction have been shown in various PD studies. In particular, patients have disrupted iron ( $\mathrm{Fe}$ ) metabolism, as well as altered mitochondrial energetics, with a decrease in mitochondrial complex I levels and overall oxidative phosphorylation in the substantia nigra (SN) [5]. Moreover, depletion of the antioxidant glutathione (GSH) is also a prominent molecular consequence in PD, with several recent studies focusing on the potential therapeutic benefits of GSH administration [6]. Together, these effects suggest an active and significant role of reactive oxygen/nitrogen species (ROS or RNS) generation in the DAergic neurodegeneration of PD. However, the exact role of oxidative stress and its timing within the pathogenesis and progression of the neurodegeneration remains an enigma, with the ever-growing list of PD-associated genes and proteins further cluttering the picture.

Many investigations into the pathophysiology behind the neurodegeneration seen in PD have focused on using rodents as a vertebrate model system. However, while their genome shows similarity to the human genome, the intricacies of the vertebrate brain have hampered fast progression in understanding the disease. For this reason, many researchers have turned to the genetically amenable Caenorhabditis elegans (C. elegans) model system. This invertebrate model contains the DAergic machinery necessary to study PD-associated neurodegeneration, as well as possessing transparent bodies that allow for in vivo visualization of neurons. In this review, C. elegans studies involving oxidative stress mechanisms associated with DAergic neurodegeneration will be discussed, including a 
special focus on the autosomal-recessive, early-onset PD-associated genes DJ-1, PINK1, PARKIN, and the major oxidative stress modulator Nrf2.

\section{C. elegans as a Model for Neurodegeneration}

The invertebrate $C$. elegans model provides several appealing advantages to investigate the connection between oxidative stress and DAergic neurodegeneration in PD. While these nematodes do not possess a brain, they do contain all necessary genetic information encoding components of the DAergic pathway [7]. This includes the homologs of the dopamine reuptake transporter (DAT, or DAT-1 in worms) [8]; the vesicular monoamine transporter 2 (VMAT2, or CAT-1 in worms) [9]; tyrosine hydroxylase (TH, or CAT-2 in worms) [10]; and dopamine receptors (D1 and D2-like receptors, or DOP-1 through DOP-4 in worms) [11]. Out of the total 302 neurons, hermaphroditic worms possess eight DAergic neurons: four CEP (cephalic) (Figure 1) and two ADE (anterior deirid) neurons in the head, as well as two PDE (posterior deirid) neurons in the tail [7]. Male worms contain six additional DAergic neurons in the tail. Neurons can be visualized through their transparent bodies

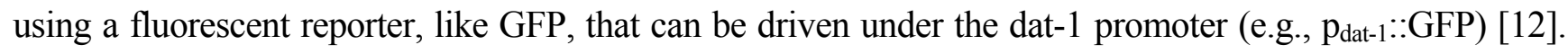
Through the use of fluorescent and confocal microscopy, degeneration can be visualized by the presence of puncta and blebbing along dendritic processes; shrinking of soma; dendritic strand breaks; and loss of soma and dendrites.

Figure 1. Arrowheads indicate the four dopaminergic cephalic (CEP) neurons in the head of the worm, with dendritic processes extending down to the tip of the nose.

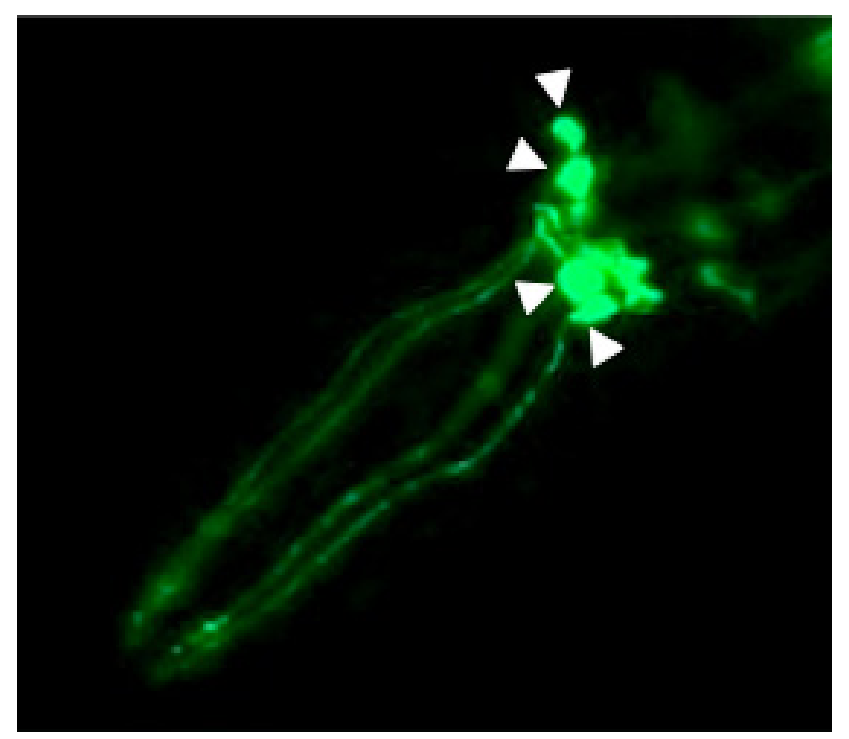

Moreover, the C. elegans genome has been fully characterized [13], allowing for ease in studying genetic models of PD and DAergic neurodegeneration. Especially with a short lifespan (two to three weeks) and a quick life cycle (three days), the ease in unbiased, forward genetic screens has made C. elegans an attractive model to study neurodegeneration in PD [14]. Nematodes are first mutagenized to induce DNA mutations, followed by the isolation of animals with distinctive phenotypes of interest. In terms of PD, these phenotypes typically involve altered DA neuronal morphology or a DA-specific behavior, like the basal slowing response (alterations in body-bending 
behavior in response to food availability) [10]. Genetic mapping of progenies showing the modified trait is used to determine the location of the altered loci included [3]. As C. elegans reproduce quickly to generate 200-300 worms in one brood, genetic screens involving large numbers of animals can be performed within a relatively short amount of time [5].

Alternatively, reverse genetics is also a simple approach to study the effects of a specific gene of interest that may be involved in neurodegeneration. Transgenesis in worms is typically accomplished through microinjection and bombardment techniques. The former involves microinjecting a plasmid containing the regulatory sequence of the gene of interest fused to a fluorescent reporter that can later be used as a readout for that gene. Similarly, subcellular targeting sequences (such as the nuclear localization signal, NLS; or the mitochondrial targeting sequence, MTS) can drive protein localization,

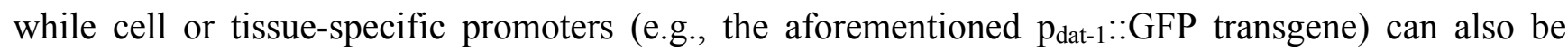
included in the plasmid to drive targeted gene expression. However, microinjection usually results in an unstable, extrachromosomal array, forcing the subsequent use of ultraviolet (UV) or gamma irradiation to integrate the transgene [15]. A second technique involves microparticle bombardment, otherwise known as biolistic transformation. Although this results in low-copy expression, the desired transgene is integrated into the genome [16].

In order to produce gene knockdowns, RNA interference (RNAi) is commonly employed in C. elegans [17]. RNAi in worms involves a systemic gene-knockdown that is dependent on RNA-dependent RNA polymerases (RdRPs) and can propagate in the F1 progeny of RNAi-exposed animals [18]. While originally conducted by microinjecting plasmids containing double-stranded RNA (dsRNA) specific to the target gene, other delivery methods include feeding worms bacteria expressing the dsRNA of interest [19] or soaking them in a dsRNA-containing solution [20]. While this technique is limited in expression specificity (some cells, such as neurons, are resistant to RNAi), there are RNAi-sensitive strains that allow for more effective knockdown (e.g., rrf-3 and eri-1 backgrounds) [21]. However, one must note that RNAi does not equally affect all tissues, along with the inherent variation in knockdown between dsRNA-fed animals. In addition to RNAi-mediated knockdown, knockout animals were formerly produced using randomized chemical mutagenesis, followed by screening for loss-of-function mutants using primers specific for deleted regions in target genes. However, a more targeted method was created using the Mos1 transposase, which cuts DNA at the location of the specific gene of interest [22]. The availability of knockout animals through the Caenorhabditis Genetics Center (CGC) is possible due to distribution of isolated deletion mutants from both the National BioResource Project of Japan (NBRP) and the C. elegans Gene Knockout Consortium (GKC) [23].

\section{Assessing Oxidative Stress in C. elegans}

\subsection{Neurotoxins: PD-Mimetics}

Some well-known pharmacological PD models in mammalian systems include the classical and highly selective neurotoxin 6-hydroxydopamine (6-OHDA), as well as 1-methyl-4-phenyl-1,2,3,6tetrahydropyridine (MPTP) and its metabolite, $\mathrm{MPP}^{+}$(1-methyl-4-phenylpyridinium ion). These toxins result in decreased ATP production, increased ROS production, and increased apoptosis of DAergic cells [24]. Similarly, herbicides and pesticides such as rotenone, paraquat, and maneb are also 
commonly used as PD models that result in increased ROS production and altered mitochondrial energetic [25]. A newer pharmacological model involves utilization of lipopolysaccharide (LPS), an inflammagen that causes production of RNS in DAergic cells via microglial activation, as another molecular feature of PD is nigrostriatal inflammation [26]. Similarly, in C. elegans, exposure to pesticides, 6-OHDA and MPTP/MPP ${ }^{+}$all result in increased oxidative stress, ATP depletion, and disrupted mitochondria that appear with the hallmark DAergic neurodegeneration [27-29]. Although the use of LPS as a PD model has not been well studied in worms, the role of other environmental toxins, such as various heavy metals, has recently emerged in C. elegans literature. As an example, manganese (Mn) exposure results in DAergic neurodegeneration that is associated with increased oxidative stress [30]; with exposure to antioxidant compounds reversing the Mn-induced ROS induction [31]. Therefore, several studies have now validated the use of the $C$. elegans model system to study the role of oxidative stress in DAergic neurodegeneration.

In studying PD, 6-OHDA is of particular interest due to its endogenous nature as a neurotoxic metabolite of DA. The endogenous production of 6-OHDA is suggested to occur via a non-enzymatic reaction between DA, hydrogen peroxide and free iron at physiological concentrations. It is also hypothesized that in vivo production of 6-OHDA is more likely to occur in the highly oxidizing environment of DA neurons [32,33]. 6-OHDA generates an increase in the production of hydrogen peroxide and free radicals, including the superoxide ion and hydroxyl radical [34,35]. These reactive oxygen species are most likely generated through the non-enzymatic breakdown of 6-OHDA or direct inhibition of complex I and IV of the mitochondrial electron transport chain [34,36,37]. The resulting ROS production from 6-OHDA breakdown leads to lipid peroxidation, protein denaturation, and increases in glutathione, which are analogous to hallmarks found in postmortem PD patients [38]. The specificity of 6-OHDA for DA neurons is due to its affinity for the $\mathrm{Na}^{+}$- and $\mathrm{Cl}^{-}$-dependent DAT [39]. Therefore, characterization of the C. elegans model of DA neurodegeneration provides an opportunity to explore fundamental questions concerning the regulation of DAT. The 6-OHDA sensitivity of the DA neurons also provides an opportunity to examine the role various endogenous and exogenous compounds, as well as proteins involved in the biosynthetic pathways of DA neurotransmission, may play in normal DA neuron function and disease.

\subsection{Measuring ROS Production in Vivo}

Considering the amount of evidence that gives rise to the theory that oxidative stress is a key factor in neurodegeneration, studying oxidative damage will bring insights to our knowledge of disease. There are several ways to assess the role of oxidative damage in neurodegeneration; one could measure levels of ROS in whole worms and in isolated mitochondria, or measure indices of oxidative damage such as measuring levels of lipid and DNA oxidation products. To investigate the role of ROS in neurodegeneration, the first logical step would involve measuring levels of intraworm ROS. Several analytical approaches (EPR, chemiluminescence, fluorescence) have been used to detect ROS. Fluorescent or chemiluminescent dyes, such as dichlorodihydrofluorescein (DCFH-DA), dihydroethidium, and dihydrorhodamine are used frequently for measuring hydrogen peroxide, superoxide, and peroxynitrite either in whole worm or isolated mitochondria [40-42]. DCFH-DA is the most widely used probe for detecting intracellular $\mathrm{H}_{2} \mathrm{O}_{2}$ and oxidative stress due to its user-friendly nature. It is 
cell-permeable and is hydrolyzed intracellularly to the DCFH carboxylate anion, which is retained in the cell. Two-electron oxidation of DCFH results in the formation of a fluorescent product, dichlorofluorescein (DCF), which can be monitored by several fluorescence-based techniques, such as fluorescent microplate readers, confocal microscopy, and flow cytometry. However, the intracellular redox chemistry of DCFH is complex, and there are several limitations and artifacts associated with the DCF assay [43-45]. DCFH does not directly react with $\mathrm{H}_{2} \mathrm{O}_{2}$ to form the fluorescent DCF product; therefore, DCF fluorescence cannot be used as a direct measure of $\mathrm{H}_{2} \mathrm{O}_{2}$. Several oxidizing species will oxidize DCFH to DCF, making the dye nonspecific for a particular form of ROS. Additionally, the intermediate radical, $\mathrm{DCF}^{\cdot-}$, rapidly reacts with $\mathrm{O}_{2}$ to form superoxide $\left(\mathrm{O}_{2}{ }^{\circ}\right)$. The dismutation of $\mathrm{O}_{2}{ }^{--}$yields additional $\mathrm{H}_{2} \mathrm{O}_{2}$ [46], which can establish a redox-cycling mechanism leading to artificial amplification of the fluorescence signal intensity. In addition, one cannot assume that control and experimental samples exhibit the same efficiency in DCF radical generation; thus, linearity should not be assumed between different treatment conditions. Therefore, it is important to recognize the limitations of the dyes and avoid erroneous interpretations; DCFH-DA probe cannot reliably measure intracellular $\mathrm{H}_{2} \mathrm{O}_{2}$ and other reactive oxygen species, but instead may be more appropriate in use as a redox indicator probe that responds to oxidative insult [47].

Recent advances in constructing genetically encoded redox-sensitive sensors have opened up new avenues for investigating redox signaling [48,49]. As mentioned earlier, fluorescent dyes are non-specific, non-linear, and disruptive; therefore real-time quantification of ROS in living organisms is limited with redox-sensitive fluorescent probes. Use of in vivo redox sensors via either a hydrogen peroxide sensor protein coupled with a glutathione redox potential sensor (Hyper and Grx1-roGFP2, respectively) [48] or quantitative redox proteomics (OxICAT) [49] can overcome limitations of the fluorescent dye to provide quantification of ROS in an intact organism. HyPer and Grx1-roGFP2 are ratiometric biosensors that can be used to determine the oxidized-to-reduced ratios of $\mathrm{H}_{2} \mathrm{O}_{2}$ and GSSG/2GSH. Yellow fluorescent protein is inserted into the $\mathrm{H}_{2} \mathrm{O}_{2}$-sensitive regulatory domain of the bacterial transcription factor (OxyR-RD) [50], and oxidation of HyPer by $\mathrm{H}_{2} \mathrm{O}_{2}$ generates a disulfide bridge between OxyR-RD to induce changes in the fluorescence of the protein, which then can be quantified. Grx1-roGFP2 detects the glutathione redox potential when HyPer gets reduced by glutaredoxin-1 (Grx1) and GSH [51]. OxICAT is a redox proteomic technique, which monitors the in vivo oxidation status of several different redox-sensitive protein thiols. A thiol-reactive isotope-coded affinity tag (ICAT) differentially labels in vivo reduced and in vivo oxidized protein thiols. High performance liquid chromatography (HPLC) is then used to separate the ICAT-labeled peptides and mass spectrometry (MS) is used to identify the thiol-containing peptides for quantification of their in vivo oxidation status. Proteins are then characterized by oxidation status and subcellular location to provide information about temporal and spatial changes in cellular redox homeostasis. The use of genetically encoded redox-sensitive sensors and redox proteomics provides efficient methods to studying ROS in intact organisms. 


\subsection{Using Pharmacological Agents to Assess the Role of ROS in Dopamine Neuron Degeneration}

Given the caveats in measuring in vivo ROS generation, researchers have instead examined sensitivity to oxidative stress, whereby increased sensitivity towards oxidative stress suggest an increased steady state level of ROS or a decreased ability to respond to ROS, which results in oxidative damage. Several compounds have been used to assess the sensitivity to oxidative stress with the most widely studied being the redox-cycling compounds, juglone [52-55], and paraquat [56-59]. Redox-cycling inducing molecules lead to generation of intracellular superoxide, and subsequent oxidative stress [60]. The application of pharmacological agents to attenuate ROS generation represents not only an indirect measurement of oxidative damage, but also exposes the worms to conditions that would normally not be encountered. It is possible that a worm may have increased ROS levels and show sensitivity towards the redox-cycling inducing molecule of choice, yet under normal conditions contains antioxidant defenses sufficient to detoxify all of the endogenous ROS produced. While the pharmacological agents for inducing oxidative stress are thought to act through ROS, in some instances, worms have been found to be sensitive to one form of oxidative stress, but not sensitive (or resistant) to another ROS generator [61-63]; therefore, experimenting with different pharmacological agents to produce the desired result may be necessary.

Typically, pro-oxidant molecules are administered to worms either during development or in young adult worms. When administered during development, sensitivity to oxidative stress is assessed by examining either the percentage of worms that are able to develop to adulthood or the furthest developmental stage obtained. Interpretation of results becomes a bit more complicated when the development time differs between the strains compared [64]. In order to obtain uniformity in comparison between strains, the slower developing strain will be exposed to the oxidative stress for a longer period. In addition to the aforementioned consideration, assays performed during development and adulthood may yield different results. Varying results could be due to high ROS production during development, which results in an increased sensitivity to oxidative stress, thus inducing the upregulation of antioxidant defenses and decreasing sensitivity to oxidative stress during data collection in adulthood. Therefore, examining sensitivity to oxidative stress at multiple developmental points is informative to these studies.

\subsection{Methods to Quantify Oxidative Damage}

Measuring levels of ROS production is not the only index of oxidative insult; quantifying the amount of oxidative damage via multiple methods can also provide valuable information in neurodegeneration studies. To measure oxidative damage, researchers have focused on either collecting products of lipid oxidation or quantifying damage to proteins. $\mathrm{F}_{2}$-Isoprostanes ((IsoPs), products of free radical-induced peroxidation of arachidonic acid)) are currently thought to be the most reliable marker of oxidative damage in humans $[65,66]$. The predominant polyunsaturated fatty acid (PUFA) in C. elegans, eicosapentaenoic acid (EPA), was also identified as an oxidative damage marker [67]; as such, measuring PUFA levels are presented as a viable approach for quantifying endogenous oxidative damage in $C$. elegans through a mass spectrophemetric-based assay of $\mathrm{F}_{3}$-IsoPs [68]. Other approaches to measure oxidative damage focuses on measuring protein 
carbonylation by derivatization with dinitrophenylhydrazine and detection with antibodies [69-71], or through detection of reactive lipid aldehydes, such as 4-hydroxynonenal (4-HNE) or isoketals (IsoK) with antibodies [72-74]. Lastly, transgenic green fluorescent protein (GFP) reporter C. elegans strains can be utilized as indirect measures of oxidative stress. Sensitivity towards juglone was assessed using a GFP transgenic reporter for the C. elegans cap " $n$ " collar transcription factor SKN-1 (the mammalian NRF-2 homolog) target gene gst-4 (glutathione-s transferase) and molecular determinants of SKN-1 activation has been studied through use of the gst-4 reporter [55,75-77].

\section{Oxidative Stress and PD-Associated Neurodegeneration in C. elegans}

\subsection{DJ-1}

The $D J-1 / P A R K 7$ gene encodes a protein of 189 amino acids, which forms a single $20 \mathrm{kDa}$ domain homologous to the prokaryotic ThiJ family, a protein involved in biosynthesis of thiamine [78]. Different pathogenic mutations (exonic deletions, truncations, and homozygous and heterozygous point mutations) in $D J-1$ have been associated with rare forms of autosomal recessive, early-onset Parkinsonism [78,79]. Therefore, the biochemical function is of central importance in shedding light on disease pathogenesis. The most well-characterized DJ-1 mutation, L166P, leads to protein destabilization and misfolding [78,80,81], and loss of dimerization necessary for functionality [82]. Several studies point out the role of DJ-1 in oxidative stress protection [83,84], mitochondrial function [85] and DAergic neuroprotection [86,87]. Additionally, it has been identified as a peroxiredoxin-like peroxidase [88] and has probable chaperone activity to prevent $\alpha$-synuclein aggregation [82]. Recent studies identified DJ-1 as a transcription regulator modulating dopamine homeostasis-related genes [87]. The DJ-1 protein responds to oxidative stress with an acidic shift by oxidation of Cys106, and the oxidized form is shuttled from the cytoplasm to mitochondria [89]. The acidic isoform has been found in higher abundance in sporadic PD brains compared to normal brains [87,90]. Evidence suggests that the acidic isoform might act as a ROS scavenger through auto-oxidation [91]. Additionally, the active cysteine site is proposed to be involved in enzymatic activities (protease, glyoxylase) of DJ-1 and binding to biological macromolecules like RNA [92]. Recently, it has been shown that dopamine-derived quinones are responsible for impairing DJ-1 function by covalently modifying Cys106 [93]. While overexpression of DJ-1 protects against dopamine toxicity and oxidative stress, DJ-1 deficiency leads to increased ROS accumulation, oxidative insults and DA neurodegeneration [87,91,94,95]. Additionally, DJ-1 mutations cause mitochondrial fragmentation [85]. DJ-1-deficient dopaminergic neurons display mitochondrial deficits, such as decreased complex I and II activity, accumulation of damaged mitochondria, and moderate oxidative stress [96]. DJ-1 is also suggested to have a key role in regulating the antioxidant capacity by regulating the expression of superoxide dismutase- 1 and superoxide dismutase-3, as well as potentially facilitating the activation of the Nrf2 pathway [97]. Mice deficient in DJ-1 are hypersensitive to oxidative stress and DAergic neurodegeneration upon MPTP treatment [98].

Recent results have also shown an interaction between $D J-1$ and two other PD-associated genes Parkin and PINK1. Up-regulation of DJ-1 can rescue PINK1, but not Parkin, resulting in protection against oxidative stress [99]. DJ-1 is also believed to be involved in promoting Parkin translocation. 
Loss of DJ-1 results in an increased stress-induced Parkin recruitment and increased mitophagy due to the loss of its ability to control ROS generation in these mutants [100]. Overexpression of either PINK1 or Parkin rescues the fragmented mitochondrial phenotype seen in DJ-1 deficient cells, suggesting that DJ-1 is acting in parallel to the PINK1/parkin pathway. However, the possibility of a DJ-1-PINK1-parkin multi-protein complex remains controversial [101,102].

DJ-1 protein is ubiquitously expressed in most mammalian tissues, including the brain, and predominantly localizes in the cytosol but can also translocate to mitochondria [103,104]. While mammals contain a single DJ-1 homolog, some species, such as Drosophila melanogaster (DJ-1 $\beta$ and $1 \alpha$ ) or C. elegans (DJR-1.1 and 1.2) contain two homologs with different tissue expression patterns. DJR-1.1 in C. elegans was detected in both the nucleus and cytoplasm of the intestinal cells, whereas DJR-1.2 is only expressed in the cytosol of head neurons [105]. The mutation of the conserved Cys106 site in DJR-1.1 in C. elegans results in abolished enzymatic activity [105]. Knocking down djr-1.1 resulted in increased vulnerability to rotenone-induced toxicity, which was rescued by treatment with a combination of D- $\beta$ hydroxybutyrate and tauroursodeoxycholic acid [106]. An additional function of DJ-1 in C. elegans is characterized by its glyoxalase activity. Detoxifying reactive glyoxals ( $\alpha$-oxoaldehydes) is of crucial importance, because they react with proteins to form advanced glycation end products, which have been implicated in the etiology of PD. Both of the DJ-1 homologs in C. elegans were characterized as glyoxylases, with DJR-1.1 being more efficient in protecting worms against glyoxals than DJR-1.2. C. elegans DJR-1.2 have also been shown to exert neuroprotective effects [105]. Furthermore, it has been demonstrated that the expression of DJR-1.2 increased dramatically when worms entered dauer stage. This expression was mediated by DAF-16, which is the

C. elegans homolog of the mammalian FoxO protein that regulates entry into the dauer stage. Additionally, djr-1.2 expression is likely to be regulated as part of the insulin signaling pathway, as confirmed by showing that daf-2 (e1370) mutants, and not the daf-2; daf-16 double mutants, show increased DJR-1.2 activity against glyoxals [107].

\subsection{Parkin and PINK1}

The PARKIN gene encodes for an E3 ubiquitin ligase, a component of the ubiquitin-proteasome system (UPS) to target substrate proteins for proteasomal degradation [108]. The protein is composed of 465 amino acids, and contains a ubiquitin-like domain that is responsible for substrate recognition, as well as RING finger domains that interact with other components of the UPS [109]. Brain PARKIN expression is distributed within basal ganglia structures, including the SN and caudate-putamen, but also with some expression in the cerebellum [110]. In addition to itself, Parkin has many substrates, including the synaptic vesicle-associated protein CDCrel-1 [108], $\alpha$-synuclein [111], the $\alpha$-synuclein-interacting protein synphilin-1 [112], and the membrane receptor Pael-R [113]. Parkin has also recently been shown to form an E3 ligase complex with DJ-1 and PINK1, two other proteins associated with PD [101]. Homozygous mutations found in PARKIN are responsible for nearly 50\% of early-onset, familial forms of PD that abnormally present without Lewy body deposition [109]. PARKIN mutants show altered intracellular localization of Parkin, along with impaired substrate binding and enzymatic activity. Consequently, a functional effect of PARKIN mutations is an inability to degrade substrate proteins [114]. PARKIN knockout mice exhibit increased extracellular striatal 
dopamine (DA) concentration [115], while wildtype Parkin seems to increase cell surface expression of the dopamine transporter (DAT) and increase DA reuptake [116]. PARKIN knockout mice also have impaired synaptic plasticity [117], as Parkin seems to negatively regulate the strength and number of excitatory synapses [118]. Moreover, animal models expressing mutant PARKIN exhibit selective DAergic degeneration as well as hypokinetic deficits [119,120], as seen in PD cases. Interestingly, Mn exposure in cells was found to increase Parkin protein levels specifically in DAergic cells. Parkin also conferred protection from Mn-induced DAergic cell death in vitro, and was selectively redistributed to the perinuclear region in DAergic cells upon Mn exposure [121]. However, the mechanism behind these effects is still unclear and needs further investigation.

Another PD-associated gene that has been strongly tied to oxidative stress is PINK1, which spans eight exons and encodes for a 581-amino acid containing kinase known as PTEN-induced kinase 1 (PINK1). While not as common in mutational frequency as PARKIN, homozygous mutations in this mitochondrial-targeted kinase also result in a familial, early-onset form of PD [122]. Reduced striatal DAT binding has been seen in PD patients who possess a G309D substitution mutation in the PINK1 gene [123], a mutation that occurs in a highly conserved region of the serine/threonine kinase domain [122]. Moreover, PINK1 knockout mice show decreased dopamine release and impaired corticostriatal synaptic plasticity [124]. In the normal human brain, PINK1 is ubiquitously expressed in all cell types, with subcellular fractionation and immunohistochemistry studies confirming a punctate, localized expression to mitochondrial membranes [125]. Its kinase domain indicates a neuroprotective role via phosphorylation of specific mitochondrial proteins to regulate proper mitochondrial function [126]. Wildtype (WT) PINK1 can protect against $\mathrm{MPP}^{+}$-induced DAergic cell death in primary neurons [127]. Moreover, studies using DAergic cell line SH-SY5Y have found that wildtype PINK1 promotes the reduction of cytochrome c release from mitochondria, as well as lowering levels of several apoptotic caspases [128]. In fibroblasts extracted from patients carrying the G309D mutation, a battery of oxidative stress markers were measured to find elevated lipid peroxidation, as well as increased levels of MnSOD, oxidized (GSSG) glutathione, total glutathione, glutathione reductase (GR), and glutathione-S-transferase (GST). The PINK1 mutant fibroblasts also showed decreased mitochondrial complex I activity that corresponded with a trend toward elevated superoxide production [129].

Interestingly, a key phosphorylation target of PINK1 is Parkin [130,131]. Initial, landmark findings show that Parkin and PINK1 work together in a common pathway to maintain mitochondrial integrity within DAergic neurons, and that Parkin functions downstream of PINK1 in this pathway [132]. Further studies found that the PINK1/parkin pathway in Drosophila actually promotes fission and inhibits fusion of mitochondria [133], and that Parkin translocation to damaged mitochondria with lowered mitochondrial membrane potential is dependent on PINK1 expression (and autophosphorylation [134]) that promotes aggregation of these mitochondria into the perinuclear region for autophagic elimination ("mitophagy") [135-137]. More recent evidence has revealed the involvement of several novel modulators of this interaction, including the mitochondrial outer membrane protein, Mitofusin 2 (Mtfn2), as a PINK-1-mediated phosphorylation target that acts as a ubiquitination substrate for Parkin [138], and is required for proper axonal projections of midbrain DAergic neurons [139]. Additionally, the role of voltage-dependent anion channels (VDACs) has also come into light, with evidence showing their recruitment of Parkin to damaged mitochondria for proper autophagy [140]. 
While these studies represent a small proportion of the expansive PINK1-Parkin literature, such remarkable results signify that PD pathophysiology could arise from ineffective clearance and trafficking of defective mitochondria due to mutations in PARKIN or PINK1, ultimately resulting in neurodegeneration. However, the selectivity of this story in the context of DAergic neurons has yet to be resolved.

In C. elegans, pdr-1 (PD related-1) is a homolog for PARKIN that shows conservation of its function as an E3 ubiquitin ligase. Similar to PARKIN, the $p d r-1$ homolog is ubiquitously expressed in the worm, and shows high expression in both cell bodies and dendrites of neurons [141]. Similarly, the PINK1 homolog in worms, pink-1, also shows conservation in having both cytoplasmic and mitochondrial localization, as well as its serine-threonine kinase domain. Moreover, in response to paraquat-induced ROS generation, pink-1 deletion mutants exhibit shortened mitochondrial cristae and neuronal axon pathfinding defects [142]. The use of nematodes to study the role of these PD-associated genes in oxidative stress-mediated neurodegeneration is relatively novel. However, new evidence has shown that the oxidative stress and subsequent DAergic neurodegeneration in C. elegans may be selective towards particular toxicants. For example, compared to wildtype worms, $p d r-1$ knockout worms show increased lethality and shortened lifespan upon exposure to methylmercury ( $\mathrm{MeHg}$ ) that correspond to increased ROS induction. However, the $p d r-1$ mutants do not show the same dopamine-dependent behavioral deficits that wildtype worms do upon MeHg exposure [143]. On the other hand, these same $p d r-1$ knockout worms also express increased lethality and shortened lifespan (Figure 2) upon Mn exposure, yet they do show enhanced Mn-induced DAergic neurodegeneration compared to wildtype worms [144].

It is important to note the role of $L R R K 2$, or leucine-rich repeat kinase 2, a gene that is the most frequent cause of autosomal-dominant, late-onset PD [145,146]. Interestingly, this gene has also been shown to interact with the aforementioned autosomal-recessive genes. LRRK2 is predominantly found in the cytoplasm but can also associate with the mitochondrial outer membrane [147]. Pathogenic mutations result in increased kinase activity [147] that result in mitochondrial dysfunction [148] and neuronal degeneration [149]. Recent evidence has also found enhanced autophagic elimination of dendritic mitochondria and calcium dysregulation in mouse cortical neurons expressing mutant LRRK2 [150]. This is interesting, as previous evidence has shown an interaction between Parkin and LRRK2 in vitro [149] and in a Drosophila model of PD [151], with Parkin able to protect against DAergic neurodegeneration induced by mutant LRRK2 [152]. In C. elegans, the homolog for LRRK2 is known as LRK-1 and is required for the polarized localization of synaptic vesicle proteins between the axon and dendrites [153]. Loss of lrk- 1 increases vulnerability to mitochondrial inhibition as seen by a decrease in survival compared to WT worms [154], with human mutant LRRK2 expression in worms resulting in increased protein oxidation and lipid peroxidation [155]. While interactions between $1 r k-1$ and other PD-associated genes in C. elegans have not yet been elucidated, it has been shown that $l r k-1$ and pink- 1 have antagonistic roles in terms of toxin-induced stress responses and axonal outgrowth. The involvement of these proteins implicates altered kinase activity in PD pathophysiology, as kinase inhibitors were recently found to prevent and reverse mutated LRRK2-induced dopaminergic-specific behavioral deficits and DAergic neurodegeneration in C. elegans [156]. 
Figure 2. Decreased lifespan in $p d r-1 \mathrm{KO}$ worms is exacerbated by $\mathrm{Mn}$ exposure. Two thousand five hundred L1 worms were treated with $\mathrm{MnCl}_{2}$ for $30 \mathrm{~min}$, washed and then plated onto NGM plates spread with OP50 bacteria. Twenty worms were plated in triplicates per group. Worms were assessed for survival each day, and transferred to fresh plates every other day, until all worms had died. Wildtype worms: N2 strain; $p d r-1 \mathrm{KO}$ : $p d r-1$ ( $g k 448)$ deletion. Compared to untreated WT animals, the other groups show a statistically significant leftward shift in lifespan (logrank test, $p<0.001$ ), with one-way ANOVA analysis on median survival finding a significantly decreased lifespan in treated WT worms $(p<0.001)$ that is enhanced in the $p d r-1 \mathrm{KO}$ animals $(p<0.001)$.

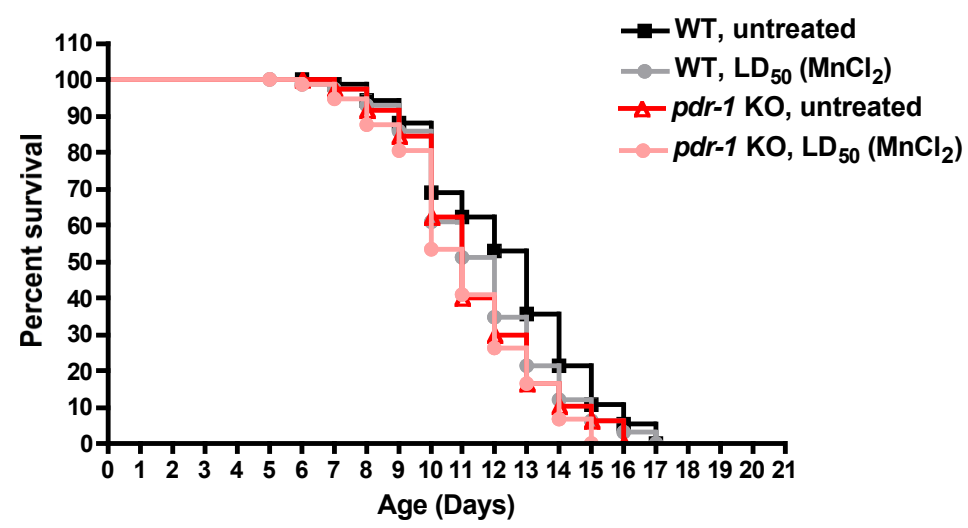

\section{3. $\mathrm{Nrf2}$}

Nuclear factor erythroid 2-related factor 2 (Nrf2) is a basic leucine zipper transcription factor. Nrf2 protects mammals from oxidative stress and age-related diseases by regulating Phase II detoxification enzymes and some antioxidant genes [157-159]. Nrf2-deficient mice show lower basal levels of Phase II enzyme expression and lack the ability to induce them $[145,160]$. Nrf2 is ubiquitously expressed in a wide range of tissues and cell types and has been identified in many species including Caenorhabditis briggsae, Drosophila melanogaster, Xenopus laevis, Mus musculus, and humans. In C. elegans, SKN-1 has been identified as a homolog of Nrf2 [161]. SKN-1 is expressed in both the intestine and in ASI neurons, and the differentially localized SKN-1 isoforms provide distinct biological functions. Expression of SKN-1 in ASI neurons is required for lifespan extension in response to dietary restriction [162]. In contrast, oxidative stress in the intestine is required to direct SKN-1 to the nuclei and promote expression of protective genes [163]. In general, activation of Nrf2 can be induced by direct modifications of Keap1 (Kelch-like ECH-associated protein 1), or phosphorylation that promotes Nrf2 stabilization [164,165]. Oxidative stress can disrupt this interaction, resulting in nuclear translocation of Nrf2 and the induction of cytoprotective genes [166,167]. However, a putative KEAP1 homolog has not been described in C. elegans.

In general, $\mathrm{SKN}-1$ activity in $C$. elegans results in the upregulation of numerous genes involved in detoxification to increased stress resistance, and in the downregulation of genes that decrease lifespan [161,162]. Global gene-expression profiles with and without $s k n-1$ (via RNAi) identified several target genes of SKN-1 under both basal conditions and oxidative stress that are directly involved in stress-related processes, including: GST (glutathione $S$-transferase), UGT (UDP-glucuronosyl/glucosyl transferase), and other Phase II genes [168-170]. For example, SKN-1 mediates stress-induced 
transcription of gst-4 (glutathione transferase-4), which has been monitored in C. elegans using strains expressing a transcriptional GFP reporter ( $\mathrm{p}_{\mathrm{gst}-4}:$ :GFP). In fact, upon exposure to $\mathrm{H}_{2} \mathrm{O}_{2}$, sodium azide and the redox cycler juglone, these worms been shown to induce gst-4 [55,75,171]. Moreover, an adaptation to oxidative stress tolerance dependent on $\mathrm{SKN}-1$ has been shown in C. elegans. $\mathrm{H}_{2} \mathrm{O}_{2}$-induced adaptation to oxidative stress was strongly dependent on an SKN-1-mediated increase in both proteolytic activity and expression of the $20 \mathrm{~S}$ proteasome. A novel role of SKN-1 has been identified in regulating synaptic transmission at neuromuscular junctions in response to stress. Additionally, SKN-1 has been determined as regulator in innate immunity suggesting its involvement in immunosenescence and providing a crosstalk between pathogenic stress signaling and the oxidative stress response [172,173].

As skn-1 mutants show reduced resistance to oxidative stress and shortened lifespan, SKN-1 overexpressing worms show a higher resistance towards oxidative stress and increased lifespan $[161,163,174]$. Consequently, in response to environmental toxins, while worms overexpressing SKN-1 showed a resistance to Mn toxicity, worms containing mutated $s k n-1$ exhibit a hypersensitive phenotype. An observed nuclear relocation of SKN-1 in ASI neurons, consistent with a Mn-induced increase in oxidative stress, further illustrated that SKN-1, at least in part, mediates Mn toxicity in worms [30]. Evidence also suggests that age affects the cytoprotective transcriptional pathway, as indicated by a decrease in the hormetic response to juglone with increased age of worms [55].

\section{Conclusions and Future Directions}

While the literature on PD-associated genes and disease pathophysiology continues to grow, the enigmatic mechanisms behind the characteristic selectivity of cell loss, mitochondrial dysfunction and increased oxidative stress remain unclear. The utilization of a model system, such as C. elegans, allows for ease in high-throughput screening and unbiased forward genetics approaches, in addition to faster genetic studies investigating the role and/or interplay of specific genes associated with the disease. While their transparent bodies allow for in vivo visualization of DAergic neurodegeneration in the nematode, further studies must be conducted to understand the selectivity associated with DAergic cell loss in PD. The list of PD-associated genes includes major redox modulators, implicating a significant role of oxidative stress in promoting the cell death seen in the disease. However, the interplay between several PD genes represents a complex scenario, which is further complicated by the role of environmental toxicants in triggering and facilitating the disease's progression.

For example, the more recent mitophagy theory connected PINK1 and Parkin proteins as co-players, working together to promote a healthy environment, free of oxidant-induced damaged mitochondria that would otherwise wreak havoc on the oxidative stress status of the cell. However, when these genes are mutated, this system is impaired, resulting in increased oxidative stress that results in DAergic neurodegeneration in the SN. What causes the selective injury within these cells remains unknown. One hypothesis posits that there are brain regions that have inherently higher frequencies of mitophagy. Thus, when proteins such as Parkin and PINK1 are impaired, these brain regions (potentially the $\mathrm{SN}$ ) become more vulnerable to oxidative damage. This is likely, as the basal ganglia are highly metabolically active [175], and consequently, may need more efficient mitochondrial turnover and trafficking to promote an environment free of oxidative stress. 
However, the question remains: why does this affect the DAergic neuronal subtype specifically in the SN, and not other cells? Dopamine itself is considered to be a strong oxidant that also produces auto-oxidization products [176]. In combination with brain region-specificity of proper mitophagy, there could also be a role that dopamine itself plays in interacting with other toxicants to produce damaging quinones and other highly reactive radicals that cause cell death within those neurons. This could coincide with the specific localization of transporters (such as DAT or the divalent metal transporter DMT1 [177]) that have been shown to transport many of the neurotoxins associated with PD. Additionally, impairment of Nrf2 in itself would be damaging to these cells, as this represents one of the primary cellular defense pathways against oxidative stress. However, in combination with exposure to a toxicant and within the environment of highly oxidative dopamine, neurodegeneration would be inevitable without a fully functioning antioxidant defense system.

Therefore, PD pathophysiology remains intricate, with a complex system of proteins and defense mechanisms that may be working together to protect against oxidative stress in neurodegeneration. Current treatment options seem to focus on the effects of dopamine supplementation and cell replacement therapy. However, these therapeutic routes are riddled with their own flaws, including detrimental side effects and the lack of sustainability in drug delivery [178]. It will be crucial that future investigations of PD have a circuit level focus on the pathophysiology found in the SN to understand how PD-associated proteins alter normal function. For example, while the use of cell lines and cultured neurons allows a glimpse into DA-specific effects, co-culture systems are more representative of neuronal networks within the brain that may be involved together in PD pathophysiology. Moreover, the newer world of optogenetics may provide an interesting avenue, even within the $C$. elegans model system, to further examine the role of PD-associated proteins within the context of intact, neural networks.

\section{Acknowledgments}

This work was funded by the Center in Molecular Toxicology NIH grant P30 ES00267, R01 ES10563, R01 ES07331, the training program in Environmental Toxicology grant T32 ES007028, the Josef Schormüller Award and the DFG (BO 4103/1-1).

\section{Conflicts of Interest}

The authors declare no conflict of interest.

\section{References}

1. Lees, A.J.; Hardy, J.; Revesz, T. Parkinson's disease. Lancet 2009, 373, 2055-2066.

2. Dawson, T.M.; Ko, H.S.; Dawson, V.L. Genetic animal models of Parkinson's disease. Neuron 2010, 66, 646-661.

3. Varcin, M.; Bentea, E.; Michotte, Y.; Sarre, S. Oxidative stress in genetic mouse models of Parkinson's disease. Oxid. Med. Cell. Longev. 2012, 2012, doi:10.1155/2012/624925.

4. Boada, J.; Cutillas, B.; Roig, T.; Bermudez, J.; Ambrosio, S. Mpp ${ }^{+}$-induced mitochondrial dysfunction is potentiated by dopamine. Biochem. Biophys. Res. Commun. 2000, 268, 916-920. 
5. Keane, P.C.; Kurzawa, M.; Blain, P.G.; Morris, C.M. Mitochondrial dysfunction in Parkinson's disease. Parkinson's Dis. 2011, 2011, doi:10.4061/2011/716871.

6. Cacciatore, I.; Baldassarre, L.; Fornasari, E.; Mollica, A.; Pinnen, F. Recent advances in the treatment of neurodegenerative diseases based on GSH delivery systems. Oxid. Med. Cell. Longev. 2012, 2012, doi:10.1155/2012/240146.

7. Sulston, J.; Dew, M.; Brenner, S. Dopaminergic neurons in the nematode Caenorhabditis elegans. J. Comp. Neurol. 1975, 163, 215-226.

8. Jayanthi, L.D.; Apparsundaram, S.; Malone, M.D.; Ward, E.; Miller, D.M.; Eppler, M.; Blakely, R.D. The Caenorhabditis elegans gene T23G5.5 encodes an antidepressant- and cocaine-sensitive dopamine transporter. Mol. Pharmacol. 1998, 54, 601-609.

9. Duerr, J.S.; Frisby, D.L.; Gaskin, J.; Duke, A.; Asermely, K.; Huddleston, D.; Eiden, L.E.; Rand, J.B. The cat-1 gene of Caenorhabditis elegans encodes a vesicular monoamine transporter required for specific monoamine-dependent behaviors. J. Neurosci. 1999, 19, 72-84.

10. Sawin, E.R.; Ranganathan, R.; Horvitz, H.R. C. elegans locomotory rate is modulated by the environment through a dopaminergic pathway and by experience through a serotonergic pathway. Neuron 2000, 26, 619-631.

11. Chase, D.L.; Koelle, M.R. Biogenic amine neurotransmitters in C. elegans. WormBook 2007, doi:10.1895/wormbook.1.132.1.

12. Nass, R.; Hall, D.H.; Miller, D.M., 3rd; Blakely, R.D. Neurotoxin-induced degeneration of dopamine neurons in Caenorhabditis elegans. Proc. Natl. Acad. Sci. USA 2002, 99, 3264-3269.

13. Consortium, C.E.S. Genome sequence of the nematode C. elegans: A platform for investigating biology. Science 1998, 282, 2012-2018.

14. Martinez-Finley, E.J.; Avila, D.S.; Chakraborty, S.; Aschner, M. Insights from Caenorhabditis elegans on the role of metals in neurodegenerative diseases. Metallomics Integr. Biomet. Sci. 2011, 3, 271-279.

15. Ahringer, J. Reverse Genetics. In Wormbook; The $C$ elegans Research Community: Cambridge, UK, 2006.

16. Isik, M.; Berezikov, E. Biolistic transformation of Caenorhabditis elegans. Methods Mol. Biol. 2013, 940, 77-86.

17. Fire, A.; Xu, S.; Montgomery, M.K.; Kostas, S.A.; Driver, S.E.; Mello, C.C. Potent and specific genetic interference by double-stranded RNA in Caenorhabditis elegans. Nature 1998, 391, 806-811.

18. Simmer, F.; Tijsterman, M.; Parrish, S.; Koushika, S.P.; Nonet, M.L.; Fire, A.; Ahringer, J.; Plasterk, R.H. Loss of the putative RNA-directed RNA polymerase RRF-3 makes C. elegans hypersensitive to RNAi. Curr. Biol. 2002, 12, 1317-1319.

19. Timmons, L.; Court, D.L.; Fire, A. Ingestion of bacterially expressed dsrnas can produce specific and potent genetic interference in Caenorhabditis elegans. Gene 2001, 263, 103-112.

20. Tabara, H.; Grishok, A.; Mello, C.C. RNAi in C. elegans: Soaking in the genome sequence. Science 1998, 282, 430-431.

21. Timmons, L. Endogenous inhibitors of RNA interference in Caenorhabditis elegans. BioEssays 2004, 26, 715-718. 
22. Frokjaer-Jensen, C.; Davis, M.W.; Hollopeter, G.; Taylor, J.; Harris, T.W.; Nix, P.; Lofgren, R.; Prestgard-Duke, M.; Bastiani, M.; Moerman, D.G.; et al. Targeted gene deletions in C. elegans using transposon excision. Nat. Methods 2010, 7, 451-453.

23. Antoshechkin, I.; Sternberg, P.W. The versatile worm: Genetic and genomic resources for Caenorhabditis elegans research. Nat. Rev. Genet. 2007, 8, 518-532.

24. Blandini, F.; Armentero, M.T. Animal models of Parkinson's disease. FEBS J. 2012, 279, 1156-1166.

25. Blesa, J.; Phani, S.; Jackson-Lewis, V.; Przedborski, S. Classic and new animal models of Parkinson's disease. J. Biomed. Biotechnol. 2012, 2012, doi:10.1155/2012/845618.

26. Hoban, D.B.; Connaughton, E.; Connaughton, C.; Hogan, G.; Thornton, C.; Mulcahy, P.; Moloney, T.C.; Dowd, E. Further characterisation of the LPS model of parkinson's disease: A comparison of intra-nigral and intra-striatal lipopolysaccharide administration on motor function, microgliosis and nigrostriatal neurodegeneration in the rat. Brain Behav. Immun. 2013, 27, 91-100.

27. Tucci, M.L.; Harrington, A.J.; Caldwell, G.A.; Caldwell, K.A. Modeling dopamine neuron degeneration in Caenorhabditis elegans. Methods Mol. Biol. 2011, 793, 129-148.

28. Ali, S.J.; Rajini, P.S. Elicitation of dopaminergic features of Parkinson's disease in C. elegans by monocrotophos, an organophosphorous insecticide. CNS Neurol. Disord. Drug Targets 2012, 11, 993-1000.

29. Wang, Y.M.; Pu, P.; Le, W.D. ATP depletion is the major cause of $\mathrm{MPP}^{+}$induced dopamine neuronal death and worm lethality in $\alpha$-synuclein transgenic C. elegans. Neurosci. Bull. 2007, 23, 329-335.

30. Benedetto, A.; Au, C.; Avila, D.S.; Milatovic, D.; Aschner, M. Extracellular dopamine potentiates Mn-induced oxidative stress, lifespan reduction, and dopaminergic neurodegeneration in a BLI-3-dependent manner in Caenorhabditis elegans. PLoS Genet. 2010, 6, e1001084.

31. Avila, D.S.; Benedetto, A.; Au, C.; Manarin, F.; Erikson, K.; Soares, F.A.; Rocha, J.B.; Aschner, M. Organotellurium and organoselenium compounds attenuate mn-induced toxicity in Caenorhabditis elegans by preventing oxidative stress. Free Radic. Biol. Med. 2012, 52, 1903-1910.

32. Jellinger, K.; Linert, L.; Kienzl, E.; Herlinger, E.; Youdim, M.B. Chemical evidence for 6-hydroxydopamine to be an endogenous toxic factor in the pathogenesis of Parkinson's disease. J. Neural Transm. Suppl. 1995, 46, 297-314.

33. Slivka, A.; Cohen, G. Hydroxyl radical attack on dopamine. J. Biol. Chem. 1985, 260, 15466-15472.

34. Cohen, G.; Heikkila, R.E. The generation of hydrogen peroxide, superoxide radical, and hydroxyl radical by 6-hydroxydopamine, dialuric acid, and related cytotoxic agents. J. Biol. Chem. 1974, 249, 2447-2452.

35. Graham, D.G.; Tiffany, S.M.; Bell, W.R., Jr.; Gutknecht, W.F. Autoxidation versus covalent binding of quinones as the mechanism of toxicity of dopamine, 6-hydroxydopamine, and related compounds toward C1300 neuroblastoma cells in vitro. Mol. Pharmacol. 1978, 14, 644-653.

36. Glinka, Y.Y.; Youdim, M.B. Inhibition of mitochondrial complexes I and II by 6-hydroxydopamine. Eur. J. Pharmacol. 1995, 292, 329-332. 
37. Glinka, Y.; Gassen, M.; Youdim, M.B. Mechanism of 6-hydroxydopamine neurotoxicity. J. Neural Transm. Suppl. 1997, 50, 55-66.

38. Jenner, P. Oxidative mechanisms in nigral cell death in Parkinson's disease. Mov. Disord. 1998, $13,24-34$.

39. Kitayama, S.; Shimada, S.; Uhl, G.R. Parkinsonism-inducing neurotoxin MPP ${ }^{+}$: Uptake and toxicity in nonneuronal cos cells expressing dopamine transporter cdna. Ann. Neurol. 1992, 32, 109-111.

40. Dingley, S.; Polyak, E.; Lightfoot, R.; Ostrovsky, J.; Rao, M.; Greco, T.; Ischiropoulos, H.; Falk, M.J. Mitochondrial respiratory chain dysfunction variably increases oxidant stress in Caenorhabditis elegans. Mitochondrion 2010, 10, 125-136.

41. Schulz, T.J.; Zarse, K.; Voigt, A.; Urban, N.; Birringer, M.; Ristow, M. Glucose restriction extends Caenorhabditis elegans life span by inducing mitochondrial respiration and increasing oxidative stress. Cell Metab. 2007, 6, 280-293.

42. Vanfleteren, J.R.; de Vreese, A. Rate of aerobic metabolism and superoxide production rate potential in the nematode Caenorhabditis elegans. J. Exp. Zool. 1996, 274, 93-100.

43. Burkitt, M.J.; Wardman, P. Cytochrome C is a potent catalyst of dichlorofluorescin oxidation: Implications for the role of reactive oxygen species in apoptosis. Biochem. Biophys. Res. Commun. 2001, 282, 329-333.

44. Bonini, M.G.; Rota, C.; Tomasi, A.; Mason, R.P. The oxidation of 2',7'-dichlorofluorescin to reactive oxygen species: A self-fulfilling prophesy? Free Radic. Biol. Med. 2006, 40, 968-975.

45. Hempel, S.L.; Buettner, G.R.; O’Malley, Y.Q.; Wessels, D.A.; Flaherty, D.M. Dihydrofluorescein diacetate is superior for detecting intracellular oxidants: Comparison with 2',7'-dichlorodihydrofluorescein diacetate, 5(and 6)-carboxy-2',7'-dichlorodihydrofluorescein diacetate, and dihydrorhodamine 123. Free Radic. Biol. Med. 1999, 27, 146-159.

46. Folkes, L.K.; Patel, K.B.; Wardman, P.; Wrona, M. Kinetics of reaction of nitrogen dioxide with dihydrorhodamine and the reaction of the dihydrorhodamine radical with oxygen: Implications for quantifying peroxynitrite formation in cells. Arch. Biochem. Biophys. 2009, 484, 122-126.

47. Kalyanaraman, B.; Darley-Usmar, V.; Davies, K.J.; Dennery, P.A.; Forman, H.J.; Grisham, M.B.; Mann, G.E.; Moore, K.; Roberts, L.J., 2nd; Ischiropoulos, H. Measuring reactive oxygen and nitrogen species with fluorescent probes: Challenges and limitations. Free Radic. Biol. Med. 2012, 52, 1-6.

48. Back, P.; de Vos, W.H.; Depuydt, G.G.; Matthijssens, F.; Vanfleteren, J.R.; Braeckman, B.P. Exploring real-time in vivo redox biology of developing and aging Caenorhabditis elegans. Free Radic. Biol. Med. 2012, 52, 850-859.

49. Knoefler, D.; Thamsen, M.; Koniczek, M.; Niemuth, N.J.; Diederich, A.K.; Jakob, U. Quantitative in vivo redox sensors uncover oxidative stress as an early event in life. Mol. Cell 2012, 47, 767-776.

50. Belousov, V.V.; Fradkov, A.F.; Lukyanov, K.A.; Staroverov, D.B.; Shakhbazov, K.S.; Terskikh, A.V.; Lukyanov, S. Genetically encoded fluorescent indicator for intracellular hydrogen peroxide. Nat. Methods 2006, 3, 281-286. 
51. Aslund, F.; Zheng, M.; Beckwith, J.; Storz, G. Regulation of the OxyR transcription factor by hydrogen peroxide and the cellular thiol-disulfide status. Proc. Natl. Acad. Sci. USA 1999, 96, 6161-6165.

52. De Castro, E.; Hegi de Castro, S.; Johnson, T.E. Isolation of long-lived mutants in Caenorhabditis elegans using selection for resistance to juglone. Free Radic. Biol. Med. 2004, 37, 139-145.

53. Inbaraj, J.J.; Chignell, C.F. Cytotoxic action of juglone and plumbagin: A mechanistic study using HaCaT keratinocytes. Chem. Res. Toxicol. 2004, 17, 55-62.

54. Hartwig, K.; Heidler, T.; Moch, J.; Daniel, H.; Wenzel, U. Feeding a ROS-generator to Caenorhabditis elegans leads to increased expression of small heat shock protein HSP-16.2 and hormesis. Genes Nutr. 2009, 4, 59-67.

55. Przybysz, A.J.; Choe, K.P.; Roberts, L.J.; Strange, K. Increased age reduces DAF-16 and SKN-1 signaling and the hormetic response of Caenorhabditis elegans to the xenobiotic juglone. Mechan. Ageing Dev. 2009, 130, 357-369.

56. Ishii, N.; Takahashi, K.; Tomita, S.; Keino, T.; Honda, S.; Yoshino, K.; Suzuki, K. A methyl viologen-sensitive mutant of the nematode Caenorhabditis elegans. Mutat. Res. 1990, 237, 165-171.

57. Khare, S.; Gomez, T.; Linster, C.L.; Clarke, S.G. Defective responses to oxidative stress in protein L-isoaspartyl repair-deficient Caenorhabditis elegans. Mech. Ageing Dev. 2009, 130, $670-680$.

58. Kim, S.C.; Sprung, R.; Chen, Y.; Xu, Y.; Ball, H.; Pei, J.; Cheng, T.; Kho, Y.; Xiao, H.; Xiao, L.; et al. Substrate and functional diversity of lysine acetylation revealed by a proteomics survey. Mol. Cell 2006, 23, 607-618.

59. Vanfleteren, J.R. Oxidative stress and ageing in Caenorhabditis elegans. Biochem. J. 1993, 292, 605-608.

60. Blum, J.; Fridovich, I. Superoxide, hydrogen peroxide, and oxygen toxicity in two free-living nematode species. Arch. Biochem. Biophys. 1983, 222, 35-43.

61. Lee, S.S.; Lee, R.Y.; Fraser, A.G.; Kamath, R.S.; Ahringer, J.; Ruvkun, G. A systematic RNAi screen identifies a critical role for mitochondria in C. elegans longevity. Nat. Genet. 2003, 33, 40-48.

62. Ventura, N.; Rea, S.; Henderson, S.T.; Condo, I.; Johnson, T.E.; Testi, R. Reduced expression of frataxin extends the lifespan of Caenorhabditis elegans. Aging Cell 2005, 4, 109-112.

63. Yamamoto, K.; Honda, S.; Ishii, N. Properties of an oxygen-sensitive mutant mev-3 of the nematode Caenorhabditis elegans. Mutat. Res. 1996, 358, 1-6.

64. Feng, J.; Bussiere, F.; Hekimi, S. Mitochondrial electron transport is a key determinant of life span in Caenorhabditis elegans. Dev. Cell 2001, 1, 633-644.

65. Montine, K.S.; Quinn, J.F.; Zhang, J.; Fessel, J.P.; Roberts, L.J., 2nd; Morrow, J.D.; Montine, T.J. Isoprostanes and related products of lipid peroxidation in neurodegenerative diseases. Chem. Phys. Lipids 2004, 128, 117-124.

66. Milne, G.L.; Yin, H.; Hardy, K.D.; Davies, S.S.; Roberts, L.J., 2nd. Isoprostane generation and function. Chem. Rev. 2011, 111, 5973-5996. 
67. Gao, L.; Yin, H.; Milne, G.L.; Porter, N.A.; Morrow, J.D. Formation of F-ring isoprostane-like compounds (F3-isoprostanes) in vivo from eicosapentaenoic acid. J. Biol. Chem. 2006, 281, 14092-14099.

68. Labuschagne, C.F.; Stigter, E.C.; Hendriks, M.M.; Berger, R.; Rokach, J.; Korswagen, H.C.; Brenkman, A.B. Quantification of in vivo oxidative damage in Caenorhabditis elegans during aging by endogenous F3-isoprostane measurement. Aging Cell 2013, 12, 214-223.

69. Adachi, H.; Fujiwara, Y.; Ishii, N. Effects of oxygen on protein carbonyl and aging in Caenorhabditis elegans mutants with long (age-1) and short (mev-1) life spans. J. Gerontol. A Biol. Sci. Med. Sci. 1998, 53, B240-B244.

70. Petriv, O.I.; Rachubinski, R.A. Lack of peroxisomal catalase causes a progeric phenotype in Caenorhabditis elegans. J. Biol. Chem. 2004, 279, 19996-20001.

71. Yanase, S.; Yasuda, K.; Ishii, N. Adaptive responses to oxidative damage in three mutants of Caenorhabditis elegans (age-1, mev-1 and daf-16) that affect life span. Mech. Ageing Dev. 2002, 123, 1579-1587.

72. Kayser, E.B.; Sedensky, M.M.; Morgan, P.G. The effects of complex I function and oxidative damage on lifespan and anesthetic sensitivity in Caenorhabditis elegans. Mech. Ageing Dev. 2004, 125, 455-464.

73. Yang, Y.Y.; Gangoiti, J.A.; Sedensky, M.M.; Morgan, P.G. The effect of different ubiquinones on lifespan in Caenorhabditis elegans. Mech. Ageing Dev. 2009, 130, 370-376.

74. Davies, S.S.; Talati, M.; Wang, X.; Mernaugh, R.L.; Amarnath, V.; Fessel, J.; Meyrick, B.O.; Sheller, J.; Roberts, L.J., 2nd. Localization of isoketal adducts in vivo using a single-chain antibody. Free Rad. Biol. Med. 2004, 36, 1163-1174.

75. Choe, K.P.; Przybysz, A.J.; Strange, K. The WD40 repeat protein WDR-23 functions with the CUL4/DDB1 ubiquitin ligase to regulate nuclear abundance and activity of SKN-1 in Caenorhabditis elegans. Mol. Cell. Biol. 2009, 29, 2704-2715.

76. Leung, C.K.; Deonarine, A.; Strange, K.; Choe, K.P. High-throughput screening and biosensing with fluorescent C. elegans strains. J. Vis. Exp. 2011, doi:10.3791/2745.

77. Leung, C.K.; Empinado, H.; Choe, K.P. Depletion of a nucleolar protein activates xenobiotic detoxification genes in Caenorhabditis elegans via Nrf/SKN-1 and p53/CEP-1. Free Radic. Biol. Med. 2012, 52, 937-950.

78. Bandyopadhyay, S.; Cookson, M.R. Evolutionary and functional relationships within the DJ1 superfamily. BMC Evol. Biol. 2004, 4, 6.

79. Bonifati, V.; Rizzu, P.; van Baren, M.J.; Schaap, O.; Breedveld, G.J.; Krieger, E.; Dekker, M.C.; Squitieri, F.; Ibanez, P.; Joosse, M.; et al. Mutations in the $d j-1$ gene associated with autosomal recessive early-onset parkinsonism. Science 2003, 299, 256-259.

80. Miller, D.W.; Ahmad, R.; Hague, S.; Baptista, M.J.; Canet-Aviles, R.; McLendon, C.; Carter, D.M.; Zhu, P.P.; Stadler, J.; Chandran, J.; et al. L166P mutant DJ-1, causative for recessive Parkinson's disease, is degraded through the ubiquitin-proteasome system. J. Biol. Chem. 2003, 278, 36588-36595.

81. Macedo, M.G.; Anar, B.; Bronner, I.F.; Cannella, M.; Squitieri, F.; Bonifati, V.; Hoogeveen, A.; Heutink, P.; Rizzu, P. The DJ-11166P mutant protein associated with early onset Parkinson's disease is unstable and forms higher-order protein complexes. Hum. Mol. Genet. 2003, 12, 2807-2816. 
82. Shendelman, S.; Jonason, A.; Martinat, C.; Leete, T.; Abeliovich, A. DJ-1 is a redox-dependent molecular chaperone that inhibits alpha-synuclein aggregate formation. PLoS Biol. 2004, 2, e362.

83. Mitsumoto, A.; Nakagawa, Y. DJ-1 is an indicator for endogenous reactive oxygen species elicited by endotoxin. Free Radic. Res. 2001, 35, 885-893.

84. Mitsumoto, A.; Nakagawa, Y.; Takeuchi, A.; Okawa, K.; Iwamatsu, A.; Takanezawa, Y. Oxidized forms of peroxiredoxins and DJ-1 on two-dimensional gels increased in response to sublethal levels of paraquat. Free Radic. Res. 2001, 35, 301-310.

85. Wang, X.; Petrie, T.G.; Liu, Y.; Liu, J.; Fujioka, H.; Zhu, X. Parkinson's disease-associated DJ-1 mutations impair mitochondrial dynamics and cause mitochondrial dysfunction. J. Neurochem. 2012, 121, 830-839.

86. Lev, N.; Ickowicz, D.; Barhum, Y.; Lev, S.; Melamed, E.; Offen, D. DJ-1 protects against dopamine toxicity. J. Neural Transm. 2009, 116, 151-160.

87. Lev, N.; Barhum, Y.; Pilosof, N.S.; Ickowicz, D.; Cohen, H.Y.; Melamed, E.; Offen, D. DJ-1 protects against dopamine toxicity: Implications for Parkinson's disease and aging. $J$. Gerontol. A Biol. Sci. Med. Sci. 2013, 68, 215-225.

88. Andres-Mateos, E.; Perier, C.; Zhang, L.; Blanchard-Fillion, B.; Greco, T.M.; Thomas, B.; Ko, H.S.; Sasaki, M.; Ischiropoulos, H.; Przedborski, S.; et al. DJ-1 gene deletion reveals that DJ-1 is an atypical peroxiredoxin-like peroxidase. Proc. Natl. Acad. Sci. USA 2007, 104, 14807-14812.

89. Canet-Aviles, R.M.; Wilson, M.A.; Miller, D.W.; Ahmad, R.; McLendon, C.; Bandyopadhyay, S.; Baptista, M.J.; Ringe, D.; Petsko, G.A.; Cookson, M.R. The Parkinson's disease protein DJ-1 is neuroprotective due to cysteine-sulfinic acid-driven mitochondrial localization. Proc. Natl. Acad. Sci. USA 2004, 101, 9103-9108.

90. Choi, J.; Sullards, M.C.; Olzmann, J.A.; Rees, H.D.; Weintraub, S.T.; Bostwick, D.E.; Gearing, M.; Levey, A.I.; Chin, L.S.; Li, L. Oxidative damage of DJ-1 is linked to sporadic Parkinson and Alzheimer diseases. J. Biol. Chem. 2006, 281, 10816-10824.

91. Taira, T.; Saito, Y.; Niki, T.; Iguchi-Ariga, S.M.; Takahashi, K.; Ariga, H. DJ-1 has a role in antioxidative stress to prevent cell death. EMBO Rep. 2004, 5, 213-218.

92. Trempe, J.F.; Fon, E.A. Structure and function of parkin, PINK1, and DJ-1, the three musketeers of neuroprotection. Front Neurol 2013, 4, 38.

93. Girotto, S.; Sturlese, M.; Bellanda, M.; Tessari, I.; Cappellini, R.; Bisaglia, M.; Bubacco, L.; Mammi, S. Dopamine-derived quinones affect the structure of the redox sensor DJ-1 through modifications at Cys-106 and Cys-53. J. Biol. Chem. 2012, 287, 18738-18749.

94. Mullett, S.J.; di Maio, R.; Greenamyre, J.T.; Hinkle, D.A. DJ-1 expression modulates astrocyte-mediated protection against neuronal oxidative stress. J. Mol. Neurosci. 2013, 49, 507-511.

95. Meulener, M.; Whitworth, A.J.; Armstrong-Gold, C.E.; Rizzu, P.; Heutink, P.; Wes, P.D.; Pallanck, L.J.; Bonini, N.M. Drosophila DJ-1 mutants are selectively sensitive to environmental toxins associated with Parkinson's disease. Curr. Biol. 2005, 15, 1572-1577.

96. Shim, J.H.; Yoon, S.H.; Kim, K.H.; Han, J.Y.; Ha, J.Y.; Hyun, D.H.; Paek, S.H.; Kang, U.J.; Zhuang, X.; Son, J.H. The antioxidant trolox helps recovery from the familial Parkinson's disease-specific mitochondrial deficits caused by PINK1- and DJ-1-deficiency in dopaminergic neuronal cells. Mitochondrion 2011, 11, 707-715. 
97. Wilhelmus, M.M.; Nijland, P.G.; Drukarch, B.; de Vries, H.E.; van Horssen, J. Involvement and interplay of parkin, PINK1, and DJ1 in neurodegenerative and neuroinflammatory disorders. Free Radic. Biol. Med. 2012, 53, 983-992.

98. Kim, R.H.; Smith, P.D.; Aleyasin, H.; Hayley, S.; Mount, M.P.; Pownall, S.; Wakeham, A.; You-Ten, A.J.; Kalia, S.K.; Horne, P.; et al. Hypersensitivity of DJ-1-deficient mice to 1-methyl-4-phenyl-1,2,3,6-tetrahydropyrindine (MPTP) and oxidative stress. Proc. Natl. Acad. Sci. USA 2005, 102, 5215-5220.

99. Hao, L.Y.; Giasson, B.I.; Bonini, N.M. DJ-1 is critical for mitochondrial function and rescues PINK1 loss of function. Proc. Natl. Acad. Sci. USA 2010, 107, 9747-9752.

100. Joselin, A.P.; Hewitt, S.J.; Callaghan, S.M.; Kim, R.H.; Chung, Y.H.; Mak, T.W.; Shen, J.; Slack, R.S.; Park, D.S. ROS-dependent regulation of parkin and DJ-1 localization during oxidative stress in neurons. Hum. Mol. Genet. 2012, 21, 4888-4903.

101. Xiong, H.; Wang, D.; Chen, L.; Choo, Y.S.; Ma, H.; Tang, C.; Xia, K.; Jiang, W.; Ronai, Z.; Zhuang, X.; et al. Parkin, PINK1, and DJ-1 form a ubiquitin E3 ligase complex promoting unfolded protein degradation. J. Clin. Invest. 2009, 119, 650-660.

102. Thomas, K.J.; McCoy, M.K.; Blackinton, J.; Beilina, A.; van der Brug, M.; Sandebring, A.; Miller, D.; Maric, D.; Cedazo-Minguez, A.; Cookson, M.R. DJ-1 acts in parallel to the PINK1/parkin pathway to control mitochondrial function and autophagy. Hum. Mol. Genet. 2011, 20, 40-50.

103. Zhang, L.; Shimoji, M.; Thomas, B.; Moore, D.J.; Yu, S.W.; Marupudi, N.I.; Torp, R.; Torgner, I.A.; Ottersen, O.P.; Dawson, T.M.; et al. Mitochondrial localization of the Parkinson's disease related protein DJ-1: Implications for pathogenesis. Hum. Mol. Genet. 2005, 14, 2063-2073.

104. Lucas, J.I.; Marin, I. A new evolutionary paradigm for the parkinson disease gene $D J-1$. Mol. Biol. Evol. 2007, 24, 551-561.

105. Lee, J.Y.; Song, J.; Kwon, K.; Jang, S.; Kim, C.; Baek, K.; Kim, J.; Park, C. Human DJ-1 and its homologs are novel glyoxalases. Hum. Mol. Genet. 2012, 21, 3215-3225.

106. Ved, R.; Saha, S.; Westlund, B.; Perier, C.; Burnam, L.; Sluder, A.; Hoener, M.; Rodrigues, C.M.; Alfonso, A.; Steer, C.; et al. Similar patterns of mitochondrial vulnerability and rescue induced by genetic modification of alpha-synuclein, parkin, and DJ-1 in Caenorhabditis elegans. J. Biol. Chem. 2005, 280, 42655-42668.

107. Lee, J.Y.; Kim, C.; Kim, J.; Park, C. DJR-1.2 of Caenorhabditis elegans is induced by DAF-16 in the dauer state. Gene 2013, 524, 373-376.

108. Zhang, Y.; Gao, J.; Chung, K.K.; Huang, H.; Dawson, V.L.; Dawson, T.M. Parkin functions as an E2-dependent ubiquitin- protein ligase and promotes the degradation of the synaptic vesicle-associated protein, CDCrel-1. Proc. Natl. Acad. Sci. USA 2000, 97, 13354-13359.

109. Kitada, T.; Asakawa, S.; Hattori, N.; Matsumine, H.; Yamamura, Y.; Minoshima, S.; Yokochi, M.; Mizuno, Y.; Shimizu, N. Mutations in the parkin gene cause autosomal recessive juvenile parkinsonism. Nature 1998, 392, 605-608.

110. Horowitz, J.M.; Myers, J.; Stachowiak, M.K.; Torres, G. Identification and distribution of parkin in rat brain. Neuroreport 1999, 10, 3393-3397. 
111. Shimura, H.; Schlossmacher, M.G.; Hattori, N.; Frosch, M.P.; Trockenbacher, A.; Schneider, R.; Mizuno, Y.; Kosik, K.S.; Selkoe, D.J. Ubiquitination of a new form of alpha-synuclein by parkin from human brain: Implications for Parkinson's disease. Science 2001, 293, 263-269.

112. Chung, K.K.; Zhang, Y.; Lim, K.L.; Tanaka, Y.; Huang, H.; Gao, J.; Ross, C.A.; Dawson, V.L.; Dawson, T.M. Parkin ubiquitinates the alpha-synuclein-interacting protein, synphilin-1: Implications for lewy-body formation in Parkinson disease. Nat. Med. 2001, 7, 1144-1150.

113. Imai, Y.; Soda, M.; Inoue, H.; Hattori, N.; Mizuno, Y.; Takahashi, R. An unfolded putative transmembrane polypeptide, which can lead to endoplasmic reticulum stress, is a substrate of parkin. Cell 2001, 105, 891-902.

114. Sriram, S.R.; Li, X.; Ko, H.S.; Chung, K.K.; Wong, E.; Lim, K.L.; Dawson, V.L.; Dawson, T.M. Familial-associated mutations differentially disrupt the solubility, localization, binding and ubiquitination properties of parkin. Hum. Mol. Genet. 2005, 14, 2571-2586.

115. Goldberg, M.S.; Fleming, S.M.; Palacino, J.J.; Cepeda, C.; Lam, H.A.; Bhatnagar, A.; Meloni, E.G.; Wu, N.; Ackerson, L.C.; Klapstein, G.J.; et al. Parkin-deficient mice exhibit nigrostriatal deficits but not loss of dopaminergic neurons. J. Biol. Chem. 2003, 278, 43628-43635.

116. Jiang, H.; Jiang, Q.; Feng, J. Parkin increases dopamine uptake by enhancing the cell surface expression of dopamine transporter. J. Biol. Chem. 2004, 279, 54380-54386.

117. Kitada, T.; Pisani, A.; Karouani, M.; Haburcak, M.; Martella, G.; Tscherter, A.; Platania, P.; $\mathrm{Wu}$, B.; Pothos, E.N.; Shen, J. Impaired dopamine release and synaptic plasticity in the striatum of parkin-/- mice. J.Neurochem. 2009, 110, 613-621.

118. Helton, T.D.; Otsuka, T.; Lee, M.C.; Mu, Y.; Ehlers, M.D. Pruning and loss of excitatory synapses by the parkin ubiquitin ligase. Proc. Natl. Acad. Sci. USA 2008, 105, 19492-19497.

119. Sang, T.K.; Chang, H.Y.; Lawless, G.M.; Ratnaparkhi, A.; Mee, L.; Ackerson, L.C.; Maidment, N.T.; Krantz, D.E.; Jackson, G.R. A drosophila model of mutant human parkin-induced toxicity demonstrates selective loss of dopaminergic neurons and dependence on cellular dopamine. J. Neurosci. 2007, 27, 981-992.

120. Lu, X.H.; Fleming, S.M.; Meurers, B.; Ackerson, L.C.; Mortazavi, F.; Lo, V.; Hernandez, D.; Sulzer, D.; Jackson, G.R.; Maidment, N.T.; et al. Bacterial artificial chromosome transgenic mice expressing a truncated mutant parkin exhibit age-dependent hypokinetic motor deficits, dopaminergic neuron degeneration, and accumulation of proteinase K-resistant alpha-synuclein. J. Neurosci. 2009, 29, 1962-1976.

121. Higashi, Y.; Asanuma, M.; Miyazaki, I.; Hattori, N.; Mizuno, Y.; Ogawa, N. Parkin attenuates manganese-induced dopaminergic cell death. J. Neurochem. 2004, 89, 1490-1497.

122. Valente, E.M.; Abou-Sleiman, P.M.; Caputo, V.; Muqit, M.M.; Harvey, K.; Gispert, S.; Ali, Z.; del Turco, D.; Bentivoglio, A.R.; Healy, D.G.; et al. Hereditary early-onset Parkinson's disease caused by mutations in PINK1. Science 2004, 304, 1158-1160.

123. Kessler, K.R.; Hamscho, N.; Morales, B.; Menzel, C.; Barrero, F.; Vives, F.; Gispert, S.; Auburger, G. Dopaminergic function in a family with the PARK6 form of autosomal recessive Parkinson's syndrome. J. Neural Transm. 2005, 112, 1345-1353.

124. Kitada, T.; Pisani, A.; Porter, D.R.; Yamaguchi, H.; Tscherter, A.; Martella, G.; Bonsi, P.; Zhang, C.; Pothos, E.N.; Shen, J. Impaired dopamine release and synaptic plasticity in the striatum of PINK1-deficient mice. Proc. Natl. Acad. Sci. USA 2007, 104, 11441-11446. 
125. Gandhi, S.; Muqit, M.M.; Stanyer, L.; Healy, D.G.; Abou-Sleiman, P.M.; Hargreaves, I.; Heales, S.; Ganguly, M.; Parsons, L.; Lees, A.J.; et al. PINK1 protein in normal human brain and Parkinson's disease. Brain J. Neurol. 2006, 129, 1720-1731.

126. Sim, C.H.; Lio, D.S.; Mok, S.S.; Masters, C.L.; Hill, A.F.; Culvenor, J.G.; Cheng, H.C. $C$-terminal truncation and Parkinson's disease-associated mutations down-regulate the protein serine/threonine kinase activity of PTEN-induced kinase-1. Hum. Mol. Genet. 2006, 15, 3251-3262.

127. Haque, M.E.; Thomas, K.J.; D’Souza, C.; Callaghan, S.; Kitada, T.; Slack, R.S.; Fraser, P.; Cookson, M.R.; Tandon, A.; Park, D.S. Cytoplasmic PINK1 activity protects neurons from dopaminergic neurotoxin MPTP. Proc. Natl. Acad. Sci. USA 2008, 105, 1716-1721.

128. Petit, A.; Kawarai, T.; Paitel, E.; Sanjo, N.; Maj, M.; Scheid, M.; Chen, F.; Gu, Y.; Hasegawa, H.; Salehi-Rad, S.; et al. Wild-type PINK1 prevents basal and induced neuronal apoptosis, a protective effect abrogated by Parkinson disease-related mutations. J. Biol. Chem. 2005, 280, 34025-34032.

129. Hoepken, H.H.; Gispert, S.; Morales, B.; Wingerter, O.; del Turco, D.; Mulsch, A.; Nussbaum, R.L.; Muller, K.; Drose, S.; Brandt, U.; et al. Mitochondrial dysfunction, peroxidation damage and changes in glutathione metabolism in PARK6. Neurobiol. Dis. 2007, 25, 401-411.

130. Kim, Y.; Park, J.; Kim, S.; Song, S.; Kwon, S.K.; Lee, S.H.; Kitada, T.; Kim, J.M.; Chung, J. PINK1 controls mitochondrial localization of parkin through direct phosphorylation. Biochem. Biophys. Res. Commun. 2008, 377, 975-980.

131. Iguchi, M.; Kujuro, Y.; Okatsu, K.; Koyano, F.; Kosako, H.; Kimura, M.; Suzuki, N.; Uchiyama, S.; Tanaka, K.; Matsuda, N. Parkin catalyzed ubiquitin-ester transfer is triggered by PINK1-dependent phosphorylation. J. Biol. Chem. 2013, 288, 22019-22032.

132. Park, J.; Lee, S.B.; Lee, S.; Kim, Y.; Song, S.; Kim, S.; Bae, E.; Kim, J.; Shong, M.; Kim, J.M.; et al. Mitochondrial dysfunction in drosophila PINK1 mutants is complemented by parkin. Nature 2006, 441, 1157-1161.

133. Deng, H.; Dodson, M.W.; Huang, H.; Guo, M. The Parkinson's disease genes PINK1 and parkin promote mitochondrial fission and/or inhibit fusion in drosophila. Proc. Natl. Acad. Sci. USA 2008, 105, 14503-14508.

134. Okatsu, K.; Oka, T.; Iguchi, M.; Imamura, K.; Kosako, H.; Tani, N.; Kimura, M.; Go, E.; Koyano, F.; Funayama, M.; et al. PINK1 autophosphorylation upon membrane potential dissipation is essential for parkin recruitment to damaged mitochondria. Nat. Commun. 2012, $3,1016$.

135. Vives-Bauza, C.; Zhou, C.; Huang, Y.; Cui, M.; de Vries, R.L.; Kim, J.; May, J.; Tocilescu, M.A.; Liu, W.; Ko, H.S.; et al. PINK1-dependent recruitment of parkin to mitochondria in mitophagy. Proc. Natl. Acad. Sci. USA 2010, 107, 378-383.

136. Narendra, D.; Tanaka, A.; Suen, D.F.; Youle, R.J. Parkin is recruited selectively to impaired mitochondria and promotes their autophagy. J. Cell Biol. 2008, 183, 795-803.

137. Kawajiri, S.; Saiki, S.; Sato, S.; Sato, F.; Hatano, T.; Eguchi, H.; Hattori, N. PINK1 is recruited to mitochondria with parkin and associates with LC3 in mitophagy. FEBS Lett. 2010, 584, 1073-1079.

138. Chen, Y.; Dorn, G.W., 2nd. PINK1-phosphorylated mitofusin 2 is a parkin receptor for culling damaged mitochondria. Science 2013, 340, 471-475. 
139. Lee, S.; Sterky, F.H.; Mourier, A.; Terzioglu, M.; Cullheim, S.; Olson, L.; Larsson, N.G. Mitofusin 2 is necessary for striatal axonal projections of midbrain dopamine neurons. Hum. Mol. Genet. 2012, 21, 4827-4835.

140. Sun, Y.; Vashisht, A.A.; Tchieu, J.; Wohlschlegel, J.A.; Dreier, L. Voltage-dependent anion channels (VDACS) recruit parkin to defective mitochondria to promote mitochondrial autophagy. J. Biol. Chem. 2012, 287, 40652-40660.

141. Springer, W.; Hoppe, T.; Schmidt, E.; Baumeister, R. A Caenorhabditis elegans parkin mutant with altered solubility couples alpha-synuclein aggregation to proteotoxic stress. Hum. Mol. Genet. 2005, 14, 3407-3423.

142. Samann, J.; Hegermann, J.; von Gromoff, E.; Eimer, S.; Baumeister, R.; Schmidt, E. Caenorhabditits elegans LRK-1 and PINK-1 act antagonistically in stress response and neurite outgrowth. J. Biol. Chem. 2009, 284, 16482-16491.

143. Martinez-Finley, E.J.; Chakraborty, S.; Slaughter, J.C.; Aschner, M. Early-life exposure to methylmercury in wildtype and PDR-1/parkin knockout C. elegans. Neurochem. Res. 2013, 38, 1543-1552.

144. Chakraborty, S.; Aschner, M. Vanderbilt University, Nashville, MI. Personal communication, 2013.

145. Zimprich, A.; Biskup, S.; Leitner, P.; Lichtner, P.; Farrer, M.; Lincoln, S.; Kachergus, J.; Hulihan, M.; Uitti, R.J.; Calne, D.B.; et al. Mutations in LRRK2 cause autosomal-dominant parkinsonism with pleomorphic pathology. Neuron 2004, 44, 601-607.

146. Funayama, M.; Hasegawa, K.; Kowa, H.; Saito, M.; Tsuji, S.; Obata, F. A new locus for Parkinson's disease (PARK8) maps to chromosome 12p11.2-q13.1. Ann. Neurol. 2002, 51, 296-301.

147. West, A.B.; Moore, D.J.; Biskup, S.; Bugayenko, A.; Smith, W.W.; Ross, C.A.; Dawson, V.L.; Dawson, T.M. Parkinson's disease-associated mutations in leucine-rich repeat kinase 2 augment kinase activity. Proc. Natl. Acad. Sci. USA 2005, 102, 16842-16847.

148. Mortiboys, H.; Johansen, K.K.; Aasly, J.O.; Bandmann, O. Mitochondrial impairment in patients with Parkinson disease with the G2019S mutation in LRRK2. Neurology 2010, 75, 2017-2020.

149. Smith, W.W.; Pei, Z.; Jiang, H.; Moore, D.J.; Liang, Y.; West, A.B.; Dawson, V.L.; Dawson, T.M.; Ross, C.A. Leucine-rich repeat kinase 2 (LRRK2) interacts with parkin, and mutant LRRK2 induces neuronal degeneration. Proc. Natl. Acad. Sci. USA 2005, 102, 18676-18681.

150. Cherra, S.J., 3rd; Steer, E.; Gusdon, A.M.; Kiselyov, K.; Chu, C.T. Mutant LRRK2 elicits calcium imbalance and depletion of dendritic mitochondria in neurons. Am. J. Pathol. 2013, 182, 474-484.

151. Venderova, K.; Kabbach, G.; Abdel-Messih, E.; Zhang, Y.; Parks, R.J.; Imai, Y.; Gehrke, S.; Ngsee, J.; Lavoie, M.J.; Slack, R.S.; et al. Leucine-rich repeat kinase 2 interacts with parkin, DJ-1 and PINK-1 in a drosophila melanogaster model of Parkinson's disease. Hum. Mol. Genet. 2009, $18,4390-4404$.

152. Ng, C.H.; Mok, S.Z.; Koh, C.; Ouyang, X.; Fivaz, M.L.; Tan, E.K.; Dawson, V.L.; Dawson, T.M.; Yu, F.; Lim, K.L. Parkin protects against LRRK2 G2019S mutant-induced dopaminergic neurodegeneration in drosophila. J. Neurosci. 2009, 29, 11257-11262. 
153. Sakaguchi-Nakashima, A.; Meir, J.Y.; Jin, Y.; Matsumoto, K.; Hisamoto, N. LRK-1, a C. elegans PARK8-related kinase, regulates axonal-dendritic polarity of SV proteins. Curr. Biol. 2007, 17, 592-598.

154. Saha, S.; Guillily, M.D.; Ferree, A.; Lanceta, J.; Chan, D.; Ghosh, J.; Hsu, C.H.; Segal, L.; Raghavan, K.; Matsumoto, K.; et al. LRRK2 modulates vulnerability to mitochondrial dysfunction in Caenorhabditis elegans. J. Neurosci. 2009, 29, 9210-9218.

155. Di Domenico, F.; Sultana, R.; Ferree, A.; Smith, K.; Barone, E.; Perluigi, M.; Coccia, R.; Pierce, W.; Cai, J.; Mancuso, C.; et al. Redox proteomics analyses of the influence of co-expression of wild-type or mutated LRRK2 and Tau on C. elegans protein expression and oxidative modification: Relevance to Parkinson disease. Antioxid. Redox Signal. 2012, 17, 1490-1506.

156. Yao, C.; Johnson, W.M.; Gao, Y.; Wang, W.; Zhang, J.; Deak, M.; Alessi, D.R.; Zhu, X.; Mieyal, J.J.; Roder, H.; et al. Kinase inhibitors arrest neurodegeneration in cell and C. elegans models of LRRK2 toxicity. Hum. Mol. Genet. 2013, 22, 328-344.

157. Kobayashi, M.; Yamamoto, M. Nrf2-Keap1 regulation of cellular defense mechanisms against electrophiles and reactive oxygen species. Adv. Enzym. Regul. 2006, 46, 113-140.

158. Lee, J.M.; Li, J.; Johnson, D.A.; Stein, T.D.; Kraft, A.D.; Calkins, M.J.; Jakel, R.J.; Johnson, J.A. Nrf2, a multi-organ protector? FASEB J. 2005, 19, 1061-1066.

159. Taguchi, K.; Motohashi, H.; Yamamoto, M. Molecular mechanisms of the Keap1-Nrf2 pathway in stress response and cancer evolution. Genes Cells 2011, 16, 123-140.

160. Chan, K.; Han, X.D.; Kan, Y.W. An important function of Nrf2 in combating oxidative stress: Detoxification of acetaminophen. Proc. Natl. Acad. Sci. USA 2001, 98, 4611-4616.

161. An, J.H.; Blackwell, T.K. SKN-1 links C. elegans mesendodermal specification to a conserved oxidative stress response. Genes Dev. 2003, 17, 1882-1893.

162. Bishop, N.A.; Guarente, L. Two neurons mediate diet-restriction-induced longevity in C. elegans. Nature 2007, 447, 545-549.

163. Tullet, J.M.; Hertweck, M.; An, J.H.; Baker, J.; Hwang, J.Y.; Liu, S.; Oliveira, R.P.; Baumeister, R.; Blackwell, T.K. Direct inhibition of the longevity-promoting factor SKN-1 by insulin-like signaling in C. elegans. Cell 2008, 132, 1025-1038.

164. Pi, J.; Bai, Y.; Reece, J.M.; Williams, J.; Liu, D.; Freeman, M.L.; Fahl, W.E.; Shugar, D.; Liu, J.; $\mathrm{Qu}, \mathrm{W}$; et al. Molecular mechanism of human Nrf2 activation and degradation: Role of sequential phosphorylation by protein kinase CK2. Free Radic. Biol. Med. 2007, 42, 1797-1806.

165. Kaspar, J.W.; Niture, S.K.; Jaiswal, A.K. Nrf2:INrf2 (Keap1) signaling in oxidative stress. Free Radic. Biol. Med. 2009, 47, 1304-1309.

166. Itoh, K.; Wakabayashi, N.; Katoh, Y.; Ishii, T.; O’Connor, T.; Yamamoto, M. Keap1 regulates both cytoplasmic-nuclear shuttling and degradation of $\mathrm{Nrf} 2$ in response to electrophiles. Genes Cells 2003, 8, 379-391.

167. McMahon, M.; Itoh, K.; Yamamoto, M.; Hayes, J.D. Keap1-dependent proteasomal degradation of transcription factor $\mathrm{Nrf} 2$ contributes to the negative regulation of antioxidant response element-driven gene expression. J. Biol. Chem. 2003, 278, 21592-21600.

168. Park, S.K.; Tedesco, P.M.; Johnson, T.E. Oxidative stress and longevity in Caenorhabditis elegans as mediated by SKN-1. Aging Cell 2009, 8, 258-269. 
169. Oliveira, R.P.; Porter Abate, J.; Dilks, K.; Landis, J.; Ashraf, J.; Murphy, C.T.; Blackwell, T.K. Condition-adapted stress and longevity gene regulation by Caenorhabditis elegans $\mathrm{SKN}-1 / \mathrm{Nrf}$. Aging Cell 2009, 8, 524-541.

170. Wang, J.; Robida-Stubbs, S.; Tullet, J.M.; Rual, J.F.; Vidal, M.; Blackwell, T.K. Rnai screening implicates a SKN-1-dependent transcriptional response in stress resistance and longevity deriving from translation inhibition. PLoS Genet 2010, 6, e1001048.

171. Link, C.D.; Johnson, C.J. Reporter transgenes for study of oxidant stress in Caenorhabditis elegans. Methods Enzymol. 2002, 353, 497-505.

172. Papp, D.; Csermely, P.; Soti, C. A role for SKN-1/Nrf in pathogen resistance and immunosenescence in Caenorhabditis elegans. PLoS Pathog. 2012, 8, e1002673.

173. Hoeven, R.; McCallum, K.C.; Cruz, M.R.; Garsin, D.A. Ce-Duox1/BLI-3 generated reactive oxygen species trigger protective SKN-1 activity via p38 MAPK signaling during infection in C. elegans. PLoS Pathog. 2011, 7, e1002453.

174. An, J.H.; Vranas, K.; Lucke, M.; Inoue, H.; Hisamoto, N.; Matsumoto, K.; Blackwell, T.K. Regulation of the Caenorhabditis elegans oxidative stress defense protein SKN-1 by glycogen synthase kinase-3. Proc. Natl. Acad. Sci. USA 2005, 102, 16275-16280.

175. Bathla, G.; Hegde, A.N. MRI and CT appearances in metabolic encephalopathies due to systemic diseases in adults. Clin. Radiol. 2013, 68, 545-554.

176. Miller, J.W.; Selhub, J.; Joseph, J.A. Oxidative damage caused by free radicals produced during catecholamine autoxidation: Protective effects of $o$-methylation and melatonin. Free Radic. Biol. Med. 1996, 21, 241-249.

177. Salazar, J.; Mena, N.; Hunot, S.; Prigent, A.; Alvarez-Fischer, D.; Arredondo, M.; Duyckaerts, C.; Sazdovitch, V.; Zhao, L.; Garrick, L.M.; et al. Divalent metal transporter 1 (DMT1) contributes to neurodegeneration in animal models of Parkinson's disease. Proc. Natl. Acad. Sci. USA 2008, 105, 18578-18583.

178. Worth, P.F. How to treat Parkinson's disease in 2013. Clin. Med. 2013, 13, 93-96.

(C) 2013 by the authors; licensee MDPI, Basel, Switzerland. This article is an open access article distributed under the terms and conditions of the Creative Commons Attribution license (http://creativecommons.org/licenses/by/3.0/). 